\title{
Airway exchange catheters: appropriate use and gas embolism
}

\author{
Kenneth M. LeDez, FRCPC
}

Received: 28 July 2011/Accepted: 13 September 2011/Published online: 10 November 2011

(C) Canadian Anesthesiologists' Society 2011

\section{To the Editor,}

A recent article in the Journal was prompted by concerns raised by the Ontario Coroner regarding the death of a young healthy male patient who received oxygen postoperatively through an airway exchange catheter (AEC). ${ }^{1}$ Valuable information was presented in the article, but additional issues require consideration, for example, postmortem details were not presented. Resuscitation in the circumstance of a unilateral tension pneumothorax warrants prompt relief by needle thoracostomy as was performed in this case. However, arterial gas embolism (AGE) (coronary and cerebral) may have also occurred. While emergency hyperbaric oxygen treatment (HBOT) is indicated for AGE, it is difficult to implement during cardiac arrest. Positive pressure ventilation during resuscitation may have contributed to possible AGE, but lung or lobe isolation using a double-lumen endotracheal tube (ETT) or bronchial blocker is important to consider. ${ }^{2}$

When the patient's jaws are wired closed, the airway may be secured in an emergency situation by cricothyroidotomy, tracheostomy, fibreoptic nasal intubation, blind nasal intubation, and/or by cutting the wires or elastics holding the patient's jaws together to enable oral tracheal intubation. Postoperatively, an alternative to using an AEC is to withdraw the nasal ETT (used intraoperatively) into the pharynx and then to re-advance the ETT either blindly over a bougie or with the aid of a fibreoptic bronchoscope if the need arises. The patient's lungs may also be ventilated manually with the supraglottic ETT by occluding the contralateral nares and mouth with one hand while applying bag-mask ventilation with the other hand.

\section{K. M. LeDez, FRCPC ( $₫)$}

Memorial University, Health Sciences Centre,

St. John's, NL, Canada

e-mail: kledez@mun.ca
When the patient is awake, cooperative, and breathing adequately, there is little justification for leaving an AEC in situ since it could damage or perforate the airway or lung, become displaced, or be connected to a source of compressed gas.

Perhaps AECs should not be supplied with the connector attached, since this implies that use for ventilation or oxygenation is a routine rather than an emergency application. It can be argued that the connectors for a breathing system or jet ventilator should be packaged separately with printed instructions specifying brief emergency use by a physician in constant attendance and warning of the danger of barotrauma and AGE and the need for chest tube insertion and HBOT. The manufacturers that produce AECs and the agencies that regulate such devices may be well advised to consider changes to packaging and instructions. The prognosis for iatrogenic AGE is very poor $^{3}$ unless treated promptly with HBOT. ${ }^{4,5}$

Disclosure There are no disclosures to be made for this publication.

Funding No source of funding was used.

Competing interests None declared.

\section{References}

1. Duggan LV, Law JA, Murphy MF. Brief review: Supplementing oxygen through an airway exchange catheter: efficacy, complications and recommendations. Can J Anesth 2011; 58: 560-8.

2. Sipos PT, Briand E, Arbutina DR. Can one lung ventilation prevent air embolism in the lung injury victim? Curr Surg 2000; 57: 349-53.

3. Bessereau J, Genotelle N, Chabbaut C, et al. Long-term outcome of iatrogenic gas embolism. Intensive Care Med 2010; 36: 1180-7.

4. Blanc P, Boussuges A, Henriette $K$, Sainty JM, Deleflie M. Iatrogenic cerebral air embolism: the importance of an early hyperbaric oxygenation. Intensive Care Med 2002; 28: 559-63. 
5. Brito T, Pithan N, Martins $G$, et al. Case reports: Hyperbaric oxygen therapy for the treatment of cerebral air embolism. Undersea Hyperb Med 2011; 38: 207-12.

\section{Reply}

We thank Dr. LeDez for his interest in our recently published article, ${ }^{1}$ and we appreciate the opportunity to respond.

Dr. LeDez raises an intriguing idea regarding the possible role of intravascular air embolism as a possible additional source of pathology when barotrauma associated with airway exchange catheters (AECs) occurs. The first cited paper by Sipos ${ }^{2}$ is an animal study where six female swine had their left lung lacerated in various locations without air emboli being detected. However, air emboli did occur in two swine when their left hilum was lacerated by a scalpel. We remain uncertain whether this pathology is similar to either the barotrauma or the direct airway trauma induced by an AEC. In the cited article by Bessereau, ${ }^{3}$ iatrogenic vascular air embolism was diagnosed secondary to a myriad of medical interventions. Central line procedures followed by thoracic, cardiac, abdominal, and interventional radiology procedures accounted for 79 of 119 patients admitted to their hyperbaric unit in Paris, France over an 11-yr period. Use of an AEC was not mentioned in any of these cases.

For clarification, a full description of the barotraumarelated pathology found in the patient we presented was not described as we wished to focus on the main point of our article, i.e., oxygenation through an AEC. To this end, we did not state the presence of a unilateral tension pneumothorax, as mentioned by Dr. LeDez. Therefore, lung isolation was not a consideration in this case.

There are various possible airway interventions in the setting of the hypoxic patient with his/her jaws wired shut. The focus of our article was on whether there is sufficient evidence in the literature to support the use of oxygen supplementation through an AEC $v s$ other conventional airway interventions, such as the maneuvers mentioned in the above letter. Currently, there is no evidence to support the use of oxygen supplementation through an AEC vs other means.

We disagree with the statement: "When the patient is awake, co-operative, and breathing adequately, there is little justification for leaving an AEC in situ since it could damage or perforate the airway or lung, become displaced, or be connected to a source of compressed gas." The exact types of patients where an AEC should be considered are the awake patient where airway swelling is potentially anticipated (e.g., anterior cervical fusion with prolonged operative time and significant intraoperative fluids) and the patient whose trachea may be difficult to re-intubate if he/she fails a trial of extubation (e.g., an extensive burn or difficult airway).
It is well known that both the number of re-intubation attempts ${ }^{4}$ and persistence with intubation attempts ${ }^{5,6}$ are associated with an increased risk of airway injury, hemodynamic complications, brain damage, and death. In Mort's study ${ }^{7}$ examining re-intubation success in intensive care unit patients undergoing a trial of extubation, the investigators showed an $87 \%$ first-pass re-intubation success rate for patients with an AEC in situ vs $14 \%$ for patients without an AEC. Furthermore, AECs are generally well tolerated in the awake patient, although we agree they can be associated with airway trauma, especially when placed beyond the trachea into the tracheobronchial tree.

Finally, we agree with Dr. LeDez that AEC manufacturers should consider supplying an AEC without a connector (whether luer-lock for jet ventilation or a 15-mm adaptor for oxygen insufflation) already attached for oxygen supplementation. Although, instead of packaging the connectors separately as suggested, it may be more prudent to package the connectors alongside the AEC with a statement regarding what we know and do not know about oxygenating through an AEC. Packaging connectors for oxygenation separately may prevent access to these devices during an emergency. Further discussion with AEC manufacturers is required.

Competing interests None declared.

\section{References}

1. Duggan LV, Law JA, Murphy MF. Brief review: Supplementing oxygen through an airway exchange catheter: efficacy, complications, and recommendations. Can J Anesth 2011; 58: 560-8.

2. Sipos PT, Briand E, Arbutina DR. Can one lung ventilation prevent air embolism in the lung injury victim? Curr Surg 2000; 57: 349-53.

3. Bessereau J, Genotelle N, Chabbaut C, et al. Long-term outcome of iatrogenic gas embolism. Intensive Care Med 2010; 36: 1180-7.

4. Mort TC. Emergency tracheal intubation: complications associated with repeated laryngoscopic attempts. Anesth Analg 2004; 99: 607-13.

5. Cook TM, Woodall N, Harper J, Benger J, Fourth National Audit Project. Major complications of airway management in the UK: results of the Fourth National Audit Project of the Royal College of Anaesthetists and the Difficult Airway Society. Part 2: intensive care and emergency departments. Br J Anaesth 2011; 106: 632-42.

6. Peterson GN, Domino KB, Caplan RA, Posner KL, Lee LA, Cheney $F W$. Management of the difficult airway: a closed claims analysis. Anesthesiology 2005; 103: 33-9.

7. Mort TC. Continuous airway access for the difficult extubation: the efficacy of the airway exchange catheter. Anesth Analg 2007; 105: 1357-62.

Laura V. Duggan, MD

University of British Columbia, Vancouver, BC, Canada

J. Adam Law, MD

Dalhousie University, Halifax, NS, Canada

Michael F. Murphy, MD

University of Alberta, Edmonton, AB, Canada 